\title{
A CONTRIBUIÇÃO DE MERLEAU-PONTY EM PESQUISAS SOBRE O “EU” DIFERENTE
}

\section{THE CONTRIBUTION OF MERLEAU-PONTY IN RESEARCHS ABOUT THE DIFFERENT "SELF”}

Vitor Gomes ${ }^{1}$

RESUMO: Trata-se de artigo que apresenta questões gerais do pensamento fenomenológico e evidencia concepções do filósofoMaurice Merleau-Ponty presentes em pesquisas educacionais acerca do indivíduo dito diferente. Evidencia a contribuição do pesquisador na compreensão da relação entre o corpo e o mundo. Compreende a realidade como produto da percepção individual. Portanto, a partir de suas concepções, depreende-se que nenhuma pesquisa é asséptica ou desprovida da humanidade do pesquisador, mas, pelo contrário, é constituída do ser/estar-mundo em suas análises. Como conclusão, apresenta a existência de um fio condutor dos estudos fenomenológicos: a busca pelo fenômeno tendo como premissa básica penetrá-lo, desvelá-lo e interpretá-lo como relação.

PALAVRAS-CHAVE: fenomenologia, percepção, pesquisa educacional.

ABSTRACT: This article presents general questions on phenomenologie thinking and makes clear philosopher's Maurice Merleau-Ponty concepts present in educational researches about person different. It shows clearly the searcher contribuition in comprehention of relation between body and world. It comprises reality as a product of individual perception. So, from his conceptions, conclude that none research is aseptic or destitute from researcher humanity, but, unlike, is composed of be/be-world in his analysis. And as a conclusion shows that regardless of the theoretical approach there is a thread of phenomenological studies: the search for the phenomenon with the basic premise penetrate it, unveil it and to elucidate it as a relation.

KEYWORDS: fenomenology, perception, educational research.

\footnotetext{
${ }^{1}$ Doutor em educação, professor do Departamento de Teorias do Ensino e Práticas Educacionais, Centro de Educação, Universidade Federal do Espírito Santo, Espírito Santo e do Programa de Pós-Graduação Mestrado Profissional em Educação (PPGMPE), Brasil.vitor.gomes@ufes.br
} 
Introdução

Etimologicamente, a fenomenologia é o estudo do fenômeno que se apresenta/manifesta,cuja visualização se dá a partir de "movimento perceptivo" do observador, numa ação interminável de seu desocultamento. O que torna complexa tal dinâmica é a necessidade do "isolamento" do observado em relação aos demais acontecimentos concomitantes; essa atitude é denominada como suspensão do fenômeno.

O objetivo ésalientar o fenômeno diante do campo de observação, não o parcializando e/ou explicando a partir de conceitos prévios, crenças ou afirmações iniciais (MARTINS; BICUDO, 1983). Em uma abordagem direta e interrogativa, o pesquisador deve descrever o fenômeno numa busca de sua hermenêutica e/ou exposição, delineando seus contornos; às vezes cobertos por um véu que, aos olhos mais sensíveis, não o mascara, masimpulsiona seu desnudamento.

Seu precursor é apontado como Franz Brentano (FORGUIERI, 1993) que, conforme Gomes(2004), influencia teóricos como: Edmund Husserl, considerado propositor de suas principais concepções; Martin Heidegger, que incorpora a fenomenologia uma hermenêutica interpretativa; e Merleau-Ponty, que a reconceitua a partir de sua fenomenologia da percepção.

Com registros iniciais do fim do século XIX, a fenomenologia, como produto de um tempo e espaço, é significada a partir de seus entornos históricos. Nesse sentido, o impacto da segunda grande guerra trouxe distintos contextos em seu pensamento, servindo como ponte para o retorno/aproximaçãodo humanismo, desta vez acrescido de concepções existencialistas, fato quea afastou (a fenomenologia) do idealismo filosófico presenteno pensamento de Husserl.

Assim, diferente da concepção de essência imutável husserliana, a partir da influência do pensamento existencialista, transforma-se (a essência) num fragmentoexpressodentro de um recorte contextual e histórico. Dessa forma: não é. Mas, sim, está2 .

É nesse contexto que surge Merleau-Ponty, que acresce à fenomenologia um viés existencialista, expresso em concepções acerca das relações entre o corpo/mundo; sujeito/objeto, apontando-as dentro de mútua imbricação; aspecto presente em sua obra: "A fenomenologia da percepção" e que, em "Sentido e sem sentido", se amplia quando aponta a relação entre a filosofia

${ }^{2} \mathrm{~A}$ essência humana não é mais imutável, mas definida emações e recortes espaçostemporais.

Rev. Fac. Educ. (Univ. do Estado de Mato Grosso), Vol. 28, Ano 15, № 2 p. 181-193, jul./dez. 2017 
e a psicologia como saberes entrelaçados (MERLEAU PONTY, 1996).

A partir da influência do pensador, a fenomenologia poderia ser descrita como possibilidade/viés/percepção de ciência que admite o caráter de manidade/humanização numa pesquisa científica, estando ela influenciada pela formação ideológica-cultural-perceptiva do pesquisador na qual, a partir de práticas/tentativas de afastamento existencial, busca sua époche, ainda que de forma parcial.

Portanto, o conceito de imparcialidade do pesquisador asséptico é colocado em xeque, agora compreendido como factível a erros, humano, sujeito carnal, e não como expressão de isenção/neutralidade, cujas análises estão dissociadas dos seus aspectos intra e extraperceptivos, inseparáveis.

Dessa forma, e inspirado por essas concepções, este artigo traz aspectos teóricos da fenomenologia de Maurice Merleau-Ponty, apresentando sua contribuição em pesquisas educacionais que trazem à tona a questão da diferença, permeadas pela ênfase da corporalidade ou por outras questões subjetivas, que, por sinal, não existem estanques, uma sem a outra.

\section{A fenomenologia de Merleau-Ponty}

O método fenomenológico possui variantes e ênfases de acordo com cada autor. Entretanto, existem concepções comuns, conceitos-base de seu pensamento. O primeiro deles é que a pesquisa fenomenológica se inicia a partir de époche,um processo intrapessoal, que significa observação não interativa, contemplativa e não diretiva, cujo produto alimentará a descrição minuciosa com o intuito de apresentar o objeto do ponto de vista de quem o observa. É a tentativa de "espaçamento" para transcender a nível pré-reflexivo ${ }^{3}$, ou seja, da mesma forma que um bebê, ter uma visão sobre algo antes de experiênciá-lo.

Nesse sentido, as aspas são sempre pertinentes, uma vez que, quando concluso, esse "processo" não se chega à essência pura, mas sim à essência compreendida/visualizada a partir da percepção particular. Trata-se, então, do testemunho, descrição a partir do vivenciado, da idiossincrasia, na qual, possivelmente, cada pesquisador terá impressões/descrições distintas.

O segundo passo é o mergulho existencial dentro do fenômeno, destacando-o em partes denominadas unidades de significado. Nesse momento, iniciase o processo de seu "desocultamento" parcial para sua posterior compreensão. Ainda que existam diferenças, derivadas da idiossincrasia dos pesquisadores

${ }^{3}$ Que recusa "pré-concepções" ou teorias explicativas sobre este.

Rev. Fac. Educ. (Univ. do Estado de Mato Grosso), Vol. 28, Ano 15, № 2 p. 181-193, jul./dez. 2017 
são perceptíveis núcleos comuns sintetizados pelos conceitos citados e que estão presentes na fenomenologia merleaupontyana.

Maurice Merleau-Ponty é considerado referência de uma "escola"4 fenomenológica da França. Estudou filosofia na Ecóle Normale Supérieure,graduando-se em 1931. Lecionou em vários liceus antes da Segunda Guerra, durante a qual serviu como oficial do Exército francês (UFSCAR, 2018). Em 1945, foi nomeado professor de filosofia da Universidade de Lyon e, em 1949, foi chamado a lecionar na Sorbonne, em Paris. Em 1952, ganhou a cadeira de filosofia no Collège de France. De 1945 a 1952, foi coeditor (com Jean-Paul Sartre) do jornal Les Temps Modernes (BEZERRA, 2018).

Suas obras mais importantes de filosofia foram de cunho epistemológico com incidência para a relação da pessoa com o mundo, o caráter antropológico e cultural, a psicanálise, a biologia e a neurociência, bem como a psicologia: "A estrutura do comportamento (1942)" e "Fenomenologia da percepção" (1945). Merleau-Ponty rompe com Husserl quando rejeita sua teoria do conhecimento intencional, fundamentando sua própria teoria no comportamento corporal e na percepção(MAURI, 2013).

Sustentava que, para a compreensão dos aspectos constituintes perceptivos é necessário considerar o organismo de forma global. Segundo Merleau-Ponty, apud Lima (2012, p. 35): “A percepção não é uma ciência do mundo, não é mesmo um ato, uma tomada de posição deliberada; ela é o fundo sobre o qual todos os atos se destacam".

Para o pensador, o conhecimento se dá na (e da) interação homem -mundo, corpo-mundo. Seu pensamento elenca as concepções de que o conhecimento científico é produto de espaços-tempos, bem como da compreensão da impossibilidade de indissociação entre sujeito e objeto. Assim, depreende o homem numa relação de imbricação social, portanto uma pesquisa é composta pelas subjetividades e percepções de seu pesquisador. Trata-se de relação indissociável entre "o quê", "como" e "quem" analisa.

Conforme o filósofo:

O mundo fenomenológico não é o ser puro, mas o sentido que transparece na intersecção das minhas experiências com as do outro, pela engrenagem de uma nas outras; ele é portanto inseparável da subjetividade e da intersubjetividade que formam sua unidade pela retomada de minhas experiências passadas em minhas experiências presentes, da experiência do outro na minha (MERLEAU-PONTY, 2011, p.18).

\footnotetext{
${ }^{4}$ Sistematizador de uma das fenomenologias.
} 
O filósofo concebe o indivíduo numa relação com o mundo a partir de seu próprio corpo, de suas percepções físicas, psicológicas e de sua realidade social. Merleau-Ponty "visualiza" o sujeito como corpo próprio, rompendo, assim, com a concepção husserliana essencialista/idealista. Dessa forma, o pensador não nega o objetivo primordial da fenomenologia (busca da essência), mas a sublinha numa busca construída a partir de "movimento" imbricado. Trata-se do que é definido por Gomes (2016, p.14) como: “[...] imbricação entre o eu e o outro, no qual, se presentifica ali a percepção e idiossincrasia do ser pesquisador".

A realidade, para Merleau-Ponty (2011), é produto da percepção individual. Logo, a partir de suas concepções, nenhuma pesquisa é asséptica ou desprovida da humanidade do pesquisador, mas, pelo contrário, é constituída do ser/estar-mundo em suas análises interpretativas.

Nesse sentido, e dentro de uma dimensão teórica de reflexão acerca da diferença, uma pergunta se faz pertinente: como as concepções do pensador se apresentam em pesquisas que falam do EU diferente, do outro que, a partir do estatístico ou do social, é rotulado como alternativo à dita "normalidade", seja pelo viés do corpo, seja pelo viés do indivíduo que difere do padrão hegemônico estabelecido em nossa realidade social?

Como pesquisador da área de educação especial, o uso do termo (diferença) se dá com intenção de sublinhamento, que evidencia e traz à tona o fragmento em relação aos aspectos gerais do fenômeno. Dessa forma, existe a afirmação deste (o fragmento), colocando-o em suspensão para seu melhor entendimento. Tal movimento reflexivo se dá a partir de opção didática deste/ neste trabalho crida como facilitadora de tal intuito.

Apresentados os conceitos iniciais e os fragmentos de uma fenomenologia da percepção, é o momento de delinear contribuições do pensamento de Merleau-Ponty nas pesquisas educacionais que abordam a temática da diferença a partir do viés físico e/ou sensorial. Para isso, serão apresentados recortes de estudos e suas cotejadas com o pensamento do filósofo. 
Conceitos de Maurice Merleau-Ponty nas pesquisas educacionais sobre 0 EU diferente

Em princípio, é necessário justificar o uso do EU. Para isso, é preciso elencar que o EU possui (numa dimensão usual) o sinônimo de indivíduo e/ou para indicar a si próprio. Contudo, seu emprego (neste artigo) se caracteriza a partir de dimensão fenomenológico-existencialista particular, possuindo o intuito de expressar o aspecto interior da pessoa, isto é, se a palavra indivíduo induz a concepção de sujeito, o EU remonta aos seus aspectos mais profundos.

Nesse sentido, o $\mathrm{EU}^{5}$ se refere à pessoa em seus aspectos mais particulares/essenciais/ intrapessoais construídos a partir da auto e heteroconstrução imagética, de sua visão/conceito interiorizada/o acerca de si próprio e do outro, edificado a partir do produto de sua apropriação e soma (dessas percepções). Trata-se da essência individual, que não é imóvel, mas se relaciona com múltiplos aspectos que envolvem o tempo, o espaço e as aprendizagens.

Assim, a opção se dá por uma questão de sentido/sentido deste pesquisador, ou seja, do sentido particular na expressão de significados, do sentido eidético ${ }^{66}$ impresso ao termo. Para além do estudo sobre o uso das concepções/inspirações em Merleau-Ponty, este trabalho foi desenvolvido a partir da influência de seu pensamento. Dito isso, é o momento da apresentação de seu diálogo e cristalização em certos estudos.

$O$ artigo "A sexualidade da pessoa com necessidade especial: sentidos e significados a partir de Gaby, uma história verdadeira", investiga a questão da sexualidade da pessoa com deficiência a partir de sua análise e dimensão cinematográfica (GOMES; MAFEZONI 2013). Teoricamente, expressa a relação entre a percepção do pesquisador e sua imbricação no processo de pesquisa. Apresenta a influência da noção da relação corpo/mundo em Merleau-Ponty, à medida que a compreende como parte da pesquisa, tendo a percepção como via dialógica na investigação dos fenômenos.

A partir da fenomenologia eidética, cujo objetivo é desvelar a essência de fenômeno vivido (HOLANDA, 2003), o trabalho "Uma reflexão fenomenológica sobre a diferença: da incompreensão a uma subjetividade inclusiva" (GOMES, 2012) apresenta a experienciação de acontecimento, pela qual uma pessoa com deficiência auditiva (surdez) tenta se comunicar sem ser compreendida. A partir disso, exerce reflexões acerca das ações de incompreensão e intolerância em relação ao outro.

${ }^{5}$ Conceito em aprimoramento utilizado por este pesquisador em suas produções a partir de 2008 .

${ }^{6}$ Da busca da essência.

Rev. Fac. Educ. (Univ. do Estado de Mato Grosso), Vol. 28, Ano 15, № 2 p. 181-193, jul./dez. 2017 
Por essa via de sentido, o artigo conclui que:

[...] é necessário transcender do Eu não entendo o que ela diz, para eu quero entender. Neste sentido, a diferença não pode se constituir como impossibilitadora do diálogo. Ou seja: o não entender é veredicto, conclusão, imobilidade e premissa da diferença como uma linha intransponível e, que não deve ser ultrapassada[...]; E querer entender não significa uma negação da diferença, já que a linha é bem clara; mas significa a compreensão da necessidade de transposição desta. É ousar e por isso muitas vezes percorrer caminhos desconhecidos para cada um de nós. $\mathrm{O}$ querer entender transcende a dificuldade e assume o risco de simplesmente não entender momentaneamente, mas querer entender, e querer significa agir (GOMES, 2012, p.11-12)

Assim, compreende:

O pensar fenomenológico é, antes de método, um estilo de vida orientado a viabilizar a compreensão da universalidade de essências e a relação entre subjetividade e intersubjetividade, justamente para que se possa perceber o Eu no Outro e o Outro que reside no $\mathrm{Eu}$. O retorno às coisas mesmas constitui etapa fundamental para a construção de soluções mais adequadas aos problemas que afligem a sociedade, sobretudo nas questões que envolvem os direitos sociais e o mínimo existencial (BARBOSA, 2012, p.1).

Para investigação do vivenciado, Gomes (2012) utiliza a Versão de Sentido criada por Mauro Martins Amatuzzi (influenciado pelo pensamento de Merleau-Ponty), que se trata do registro imediato (por escrito) da experiência com o intuito de desvelamento do fenômeno a partir de sua vivência imediata, tendo como compreensão que tal ato tende a se constituir como registro mais rico em termos de descrição perceptiva (AMATUZZI, 2010). Nesse aspecto, as concepções de Merleau-Ponty se manifestam à medida que ele compreende e valoriza o processo de imbricação como constituinte dos resultados.

"As concepções de alunos da educação à distância acerca do processo de inclusão da pessoa com necessidades especiais na rede regular de ensino" (GOMES; MAFEZONI, 2012), apresentam o conceito de sentido/sentido,que consiste na interpretação perceptiva do pesquisador perante o vivenciado. $O$ trabalho desvela, a partir de depoimentos de alunos num curso superior na 
modalidade a distância (expressos em fórum virtual), a evidenciação de suas concepções acerca do processo de inclusão da pessoa público-alvo da educação especial na rede regular de ensino. Dentre suas conclusões, delineia a relação entre as falas dos estudantes e sua imbricação vivencial com pessoas público-alvo da educação especial. Nesse sentido, os que experienciaram suas convivências evidenciam a escola regular como espaço integrador e includente para tais indivíduos.

No artigo "Obesidade e grupo: contribuições de Merleau-Ponty" (OLIVEIRA, 2010), o autor apresenta a noção da autopercepção da pessoa obesa como produtora da representação psicológica, biológica e sociológica de seu corpo e que determinará suas relações com o mundo em que vive. A relação corpo-mundo do pensador é desvelada a partir das relações de autoconceito e sua produção com base no contato com o outro.

O estudo "Corpo, percepção e conhecimento em Merleau-Ponty" (NOBREGA, 2008) tem como objetivo evidenciar a revisão conceitual sobre a percepção (realizada pelo pensador), bem como sobre o diálogo com a arte e a ciência, construindo os conceitos de uma fenomenologia do conhecimento. Novamente aqui se manifesta a concepção teórica de sujeito e objeto como imbricados.

Em "Entre a filosofia e a ciência: Merleau-Ponty e a psicologia", encontramos em seu resumo:

\begin{abstract}
Merleau-Ponty abordou um problema da tradição filosófica que se agudizou após o desenvolvimento das ciências humanas: a discordância entre a visão que o homem pode ter de si mesmo pela reflexão ou consciência e aquela que se obtém relacionando [...] às condições externas das quais elas dependem. Merleau-Ponty procurou resolver essa discordância à luz das próprias experiências das ciências, particularmente, da psicologia. Segundo ele, essas experiências demandam uma revisão da ontologia moderna. Neste contexto, no presente artigo, abordamos algumas facetas do diálogo estabelecido por Merleau-Ponty com a psicologia. Apresentamos uma leitura de questões tratadas, sobretudo em seus trabalhos iniciais (VERISSIMO; FURLAN, 2007, p.1).
\end{abstract}

Nessa abordagem, é possível identificar a influência do pensador no que se refere à noção de sujeito e seu papel construtivo/interpretativo da realidade dentro da relação Eu-Outro-mundo. Concepção comum ao trabaIho "Um diálogo fenomenológico com a educação social: experiências de um educador"(GOMES 2013), que apresenta a história de um músico erudito e Rev. Fac. Educ. (Univ. do Estado de Mato Grosso), Vol. 28, Ano 15, № 2 p. 181-193, jul./dez. 2017 
sua trajetória resiliente que o transforma em educador social. Esse processo é permeado por práticas (re)inventivas e criativas que desvelam singular psicopedagogia instintiva cômica, cuja via alimentadora se dá a partir do sujeito carnal.

Por fim, o artigo "O cinema como possibilidade de inclusão: uma oportunidade de educar o outro" (PIROVANE; GOMES, 2012) discute, dentro da produção cinematográfica "O 8 o dia" (de Jaco Von Dormael), o conceito de intencionalidade e de inclusão da pessoa com deficiência intelectual com base o viés da relação corpo e mundo de Merleau-Ponty. Analisa os possíveis sentidos produzidos no espectador e sua relação com o viés conceitual intuído pelo diretor do filme.

Assim expressa:

Não basta apenas uma fruição do filme, mas também, o diálogo e reflexões após este, procurando detalhar e apresentar diante da percepção de cada um de seus espectadores seus conteúdos e fenômenos que emergem diante de tal observação, expressando assim os seus sentidos particulares diante aos conteúdos cinematográficos. Assim, é preciso construir um olhar investigativo ao analisar o teor, buscando compreender a intencionalidade de diretores e autores ao apresentarem a história de uma determinada forma, valorizando ou não personagens, contextos, recursos e falas (PIROVANE; GOMES, 2012, p. 60).

Conforme visto nas pesquisas descritas, o anteparo teórico-existencialista merleaupontyano é vigente, sobretudo no que se refere à concepção da relação corpo-mundo/eu-mundo, em que a percepção do outro (e da realidade) se dá a partir de si mesmo, por meio de processo de construção sócio, histórico e biossocial, no qual a vivência com a diferença se faz presente.

As contribuições do pensamento de Merleau-Ponty expresso nos estudos descritos e comuns a várias pesquisas em educação personificam-se na apresentação do homem como sujeito imerso do/no mundo, numa relação de mútua dependência. Nesse sentido, apresenta-o como sujeito histórico, cujas concepções são sujeitas ao seu tempo e contexto. Sua ciência do outro e do mundo não se constitui em produto híbrido, mas fruto de imbricação de subjetividades. 


\section{Conclusões}

O mundo fenomenológico não é um conjunto separado de coisas, pessoas, animais, vegetais e minerais existentes em si mesmos e que nossas ideias representam ao transformá-los em objetos de conhecimento. Pelo contrário, o universo fenomenológico é composto por aquilo que simplesmente está imbricado com os olhares, nos quais não existe uma superioridade, mas sim um complexo processo de inter-relações.

Assim, numa perspectiva de Merleau-Ponty, a realidade é compreendida como conjunto de significados (sentidos) que são produzidos pela consciência, que partem das percepções individuais ou da razão. Destarte, ela (a razão) é "doadora de sentido", constituindo a realidade não como existência dos seres, mas num sistema de significações que depende da estrutura da própria consciência.

Dessa forma, dentro das concepções do filósofo, a noção de essência é relativizada, pois não é compreendida como instância final/imutável do ser, mas como o ponto mais denso que a percepção possa capturar dentro de um espaço-tempo.

No que tange à époche, evidencia a parcialidade de sua realização, uma vez que é indissociável a percepção do pesquisador da totalidade de concepções prévias sobre um fenômeno. Neste sentido, a époche é conceituada como processo correlato às particularidades de cada pesquisador; compreendendo o distanciamento como passo necessário; entretanto, relativo, uma vez que não é possível se afastar plenamente de emoções e sentimentos.

A fenomenologia de Merleau-Ponty evidencia as fragilidades do ser pesquisador à medida que desconstrói a noção de imparcialidade relacionada com sujeito e o objeto. Portanto, apresenta a imbricação da produção científica como reflexo de combinação entre eu corpo/o outro/a e o mundo, na constituição do pesquisador e sua influência na produção de seu olhar diante do fenômeno.

As conexões exercidas das pesquisas com fragmentos compreensivos do pensador dão-se a partir das limitações perceptivas particulares. Portanto, a depreensão de significados é constituída a partir do olhar do pesquisador em suas inter-relações e influências, sendo, assim, limitada ao particular diante da vivência do fenômeno. Nessa perspectiva e, num ato afirmativo, intui/ interpreta/vivencia/depreende o filósofo como fomentador de relevantes contribuições para o pensamento fenomenológico.

$\mathrm{Na}$ intenção de finalizar, sem concluir, é necessário compreender, 
seja numa perspectiva de Husserl, seja dentro dos aspectos intraperceptivos e corporais de Merleau-Ponty, seja numa dimensão interpretativa heideggeriana, que a fenomenologia tem um ponto em comum: a busca e o mergulho no fenômeno, tendo como premissa básica penetrá-lo, desvelá-lo e/ou interpretá-lo como relação.

\section{Referências}

AMATUZZI, Mauro Martins. Por uma psicologia humana. São Paulo: Alínea, 2010.

BEZERRA, Katharyne. Filosofia de Merleau-Ponty. Disponível em: <https:// www.estudopratico.com.br/filosofia-de-merleau-ponty/>. Acesso em: 20 fev. 2018.

FORGHIERI, Yolanda Cintrão. Psicologia fenomenológica: fundamentos, método e pesquisas. São Paulo: Pioneira, 1993.

GOMES,
cia: teorias

GOMES, Vitor. Três formas de ser resiliente:(des)velando a resiliência no espaço escolar. 2004. 159f. Dissertação (Mestrado em Educação). Programa de Pós-Graduação em Educação. Universidade Federal do Espírito Santo. Vitória: Ufes, 2004.

GOMES, Vitor. Um diálogo fenomenológico com a educação social: experiências de um educador. Revista da Faed. Cáceres, v. 20, ano 11, n. 2, 2013, p. 127-137.

. Uma reflexão fenomenológica sobre a diferença: da incompreensão a uma subjetividade inclusiva. In: SEMINÁRIO NACIONAL DE EDUCAÇÃO ESPECIAL, 2.; SEMINÁRIO CAPIXABA DE EDUCAÇÃO INCLUSIVA, 13., 2012, Vitória-ES. A educação especial no cenário brasileiro: indícios, registros e práticas de inclusão. Vitória-ES: Programa de Pós-Graduação em Educação, 2012. v. 1.

GOMES, Vitor; MAFEZONI, Andressa.Sexualidade e necessidade especial: lições e reflexões a partir de Gaby, uma história verdadeira. In: SEMINÁRIO INTERNACIONAL AS REDES EDUCATIVAS E AS TECNOLOGIAS, 7., 2013, Rio De Janeiro. As redes educativas e as tecnologias: transformações e subversões na atualidade. Rio de Janeiro: Uerj, 2013. v. 1. p. 1. 
. As Concepções de alunos da educação a distância acerca do processo de inclusão da pessoa com necessidades educacionais especiais na rede regular de ensino. In: SEMINÁRIO NACIONAL DE EDUCAÇÃO ESPECIAL, 2.; SEMINÁRIO CAPIXABA DE EDUCAÇÃO INCLUSIVA, 13., 2012, Vitória-ES. A educação especial no cenário brasileiro: indícios, registros e práticas de inclusão. Vitória-ES: Programa de Pós-Graduação em Educação, 2012. v. 1.

HOLANDA, Adriano Furtado. Pesquisa fenomenológica e psicologia eidética: elementos para um entendimento metodológico. In: BRUNS, Maria Alves de Toledo; HOLANDA, Adriano Furtado(Org.).Psicologia e fenomenologia: reflexões e perspectivas. Campinas: Alínea, 2003.

LIMA, Antônio Balbino Marçal. Merleau-Ponty e a questão do corpo nas ciências humanas. Saberes em perspec., Jequié, v. 2,n. 3, maio/ago, 2012, p.29-40. Disponível em:<http://www.saberesemperspectiva.com.br/index. php/saberesemperspectiva/article/viewFile/art2/pdf_6>. Acesso em: 9 maio. 2017.

MARTINS, Joel; BICUDO, Maria Aparecida Viggiani. Estudos sobre existencialismo, fenomenologia e educação. São Paulo: Moraes, 1983.

MAURI, Renato Garibaldi. O corpo através da perspectiva filosófica. Revista Acta Científica. Unasp, v. 22, n. 1, jan/abr , 2013, p. 37-46.

MERLEAU PONTY, Maurice. Fenomenologia da percepção. Tradução de Carlos Alberto de Moura. 4. ed. São Paulo: WMF Martins Fontes, 2011.

MERLEAU PONTY, Maurice. Sens et non-sens. Paris: Gallimard, 1996.

NOBREGA, Terezinha Petrucia da. Corpo, percepção e conhecimento em Merleau-Ponty. Estud. Psicol. (Natal) , Natal, v. 13, n. 2, ago, 2008, p.141-148. Disponível em: <http://www.redalyc.org/articulo.oa?id=26113602006>. Acesso em: 16 jun. 2017.

OLIVEIRA, Valmir Aparecido de et al . Obesidade e grupo: a contribuição de Merleau-Ponty. Vínculo, São Paulo, v. 7, n. 1, jun, 2010, p.45-54 . Disponível em <http://pepsic.bvsalud.org/pdf/vinculo/v7n1/v7n1a06.pdf >. Acesso em: 16 jun. 2017.

PIROVANE, Thalitta Pereira; GOMES, Vitor. O cinema como possibilidade de inclusão: uma oportunidade de educar o outro. Pró-Discente: Caderno de Prod. Acad.- Cient.Pos-Grad. Educ.,Vitória-ES, v. 18,n. 1,jan./jul. 2012, p.57-69.

VERISSIMO, Danilo Saretta; FURLAN, Reinaldo. Entre a filosofia e a ciência: Merleau-Ponty e a Psicologia. Paidéia,.Ribeirão Preto, v 17, n. 38. dez., 
2007, p. 331-342. Disponível em <http://www.scielo.br/pdf/paideia/v17n38/ v17n38a04.pdf>. Acesso em: 16 jun. 2017.

UNIVERSIDADE FEDERAL SE SÃO CARLOS (UFSCAR). Biografias: Maurice Merleau-Ponty. Disponível em:<http://www.ufscar.br/ defmh/spqmh/bio_ponty.html>. Acesso em 19 fev. 2018

Data de recebimento: 20.06 .2017 Data de aceite: 11.03.2018 